\title{
The Sandwich Denture-A Novel Way to reduce Ridge Resorption
}

\author{
Siddharth Bansal, Meena Aras, Vidya Chitre
}

\begin{abstract}
Many edentulous patients with severely resorbed ridge complain of loss of retention and discomfort with the use of conventional complete dentures. Basic principles of retention, stability and support are lost in these patients as overlying mucosa is thin and nonresilient. This article describes a case report of a 52-year-old completely edentulous female patient with severely resorbed mandibular ridge where a novel technique was used by sandwiching a layer of permanent soft resilient liner (Molloplast-B) between the denture teeth and denture base to reduce traumatic impact of masticatory forces on residual ridges and thereby reducing the residual ridge resorption. The resilient layer acts as a 'shock absorber' or 'stress distributor'.
\end{abstract}

Keywords: Resilient liner, Neutral zone, Split packing technique.

How to cite this article: Bansal S, Aras M, Chitre V. The Sandwich Denture-A Novel Way to reduce Ridge Resorption. Int J Prosthodont Restor Dent 2013;3(2):68-71.

Source of support: Nil

Conflict of interest: None

\section{INTRODUCTION}

As De Van stated 'the preservation of which remains is of utmost importance and not the meticulous replacement of that which has been lost'. In the light of the present statement, the mere replacement of the lost teeth in completely edentulous patients, does not amount to complete prosthetic rehabilitation of the patient but steps to preserve underlying supporting tissues is to be borne in mind.

Many edentulous patients with severely resorbed ridges complain of loss of retention and discomfort with the use of conventional complete dentures. Basic principles of retention, stability and support are lost in these patients as lining mucosa is thin and nonresilient. These patients are unable to tolerate occlusal forces during functional and parafunctional movements, resulting in complaints about pain during mastication, which is usually seen in edentulous mandible with smaller area of fitting surface compared to maxilla., ${ }^{1,2}$

In order to reduce traumatic impact to residual ridges by distributing masticatory pressure, Parker introduced a novel way by sandwiching a resilient layer between the denture teeth and denture base. ${ }^{3}$ The layer acts as a 'shock absorber' or 'stress distributor'. The resilient material is compressed in function and absorbs some of the kinetic energy applied to the teeth so that the hard basal seat of the denture receives less impact force. Part of the kinetic energy is dissipated in the deformation of resilient layer.

\section{CASE REPORT}

This article describes a step-by-step procedure for fabricating a sandwich denture using a modification of the technique used for processing conventional dentures.

\section{Technique}

A 52-year-old female completely edentulous patient with severely resorbed lower ridge reported to the Department of Prosthodontics, Goa Dental College and Hospital, with the chief complaint of difficulty in chewing due to missing teeth. There was no relevant medical history affecting prosthodontic treatment. Treatment plan decided for this patient was the conventional maxillary complete denture and mandibular sandwich denture. Master casts were obtained after following conventional materials and techniques.

Thin sheet of heat cured processed denture base (DPI, India) was fabricated for mandibular ridge to provide a permanent record base for packing the soft resilient liner (Molloplast ${ }^{\circledR}$ B-DETAX dental, Germany) against it. Wax rims were adjusted and jaw relations were recorded. Casts were mounted on a three point articulator with wax rims and three acrylic resin occlusal stoppers with horizontal orthodontic wire were attached on the lower record base for retaining the recording material (Visco-Gel, Dentsply Ltd, USA) during neutral zone recording (Figs 1A and B).

\section{Neutral Zone Recording}

A thick mix of tissue conditioner material (Visco-Gel, Dentsply Ltd, USA) in liquid/powder ratio $=1 / 1.5$ was mixed and placed around the rest of the lower base plate distally and mesially to the height of occlusal stoppers, with the upper wax rim in the mouth. The patient was instructed to talk, swallow, lick, suck, purse her lips and drink water several times so that lingual and buccal surfaces of the tissue conditioner impression were molded according to the functional movements to record neutral zone.

The lower record base was placed back on the mandibular cast (Fig. 1C). Matrices of condensation silicone (Zetaplus, Zhermack, Italy) were prepared in three sections on lingual and labial surfaces of impression of the neutral zone (Fig. 2A). Lower teeth were arranged with the guidance of these silicone matrices (Fig. 2B).

Try in of waxed dentures and flasking was done in the usual manner. Maxillary denture was processed in 

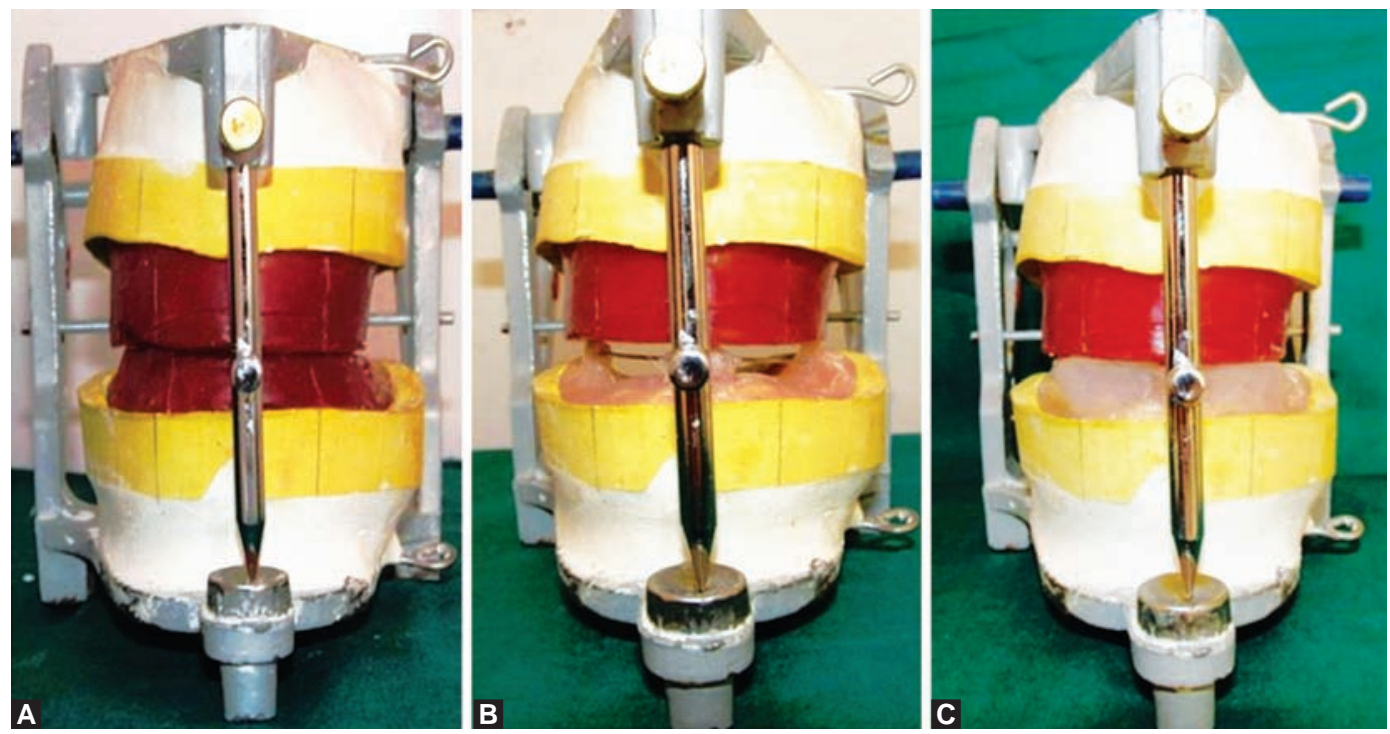

Figs 1A to C: (A) Casts with wax rims mounted on a three point articulator, (B) acrylic resin occlusal stoppers with horizontal orthodontic wire attached on the lower record base, $(C)$ neutral zone recorded with Visco-gel
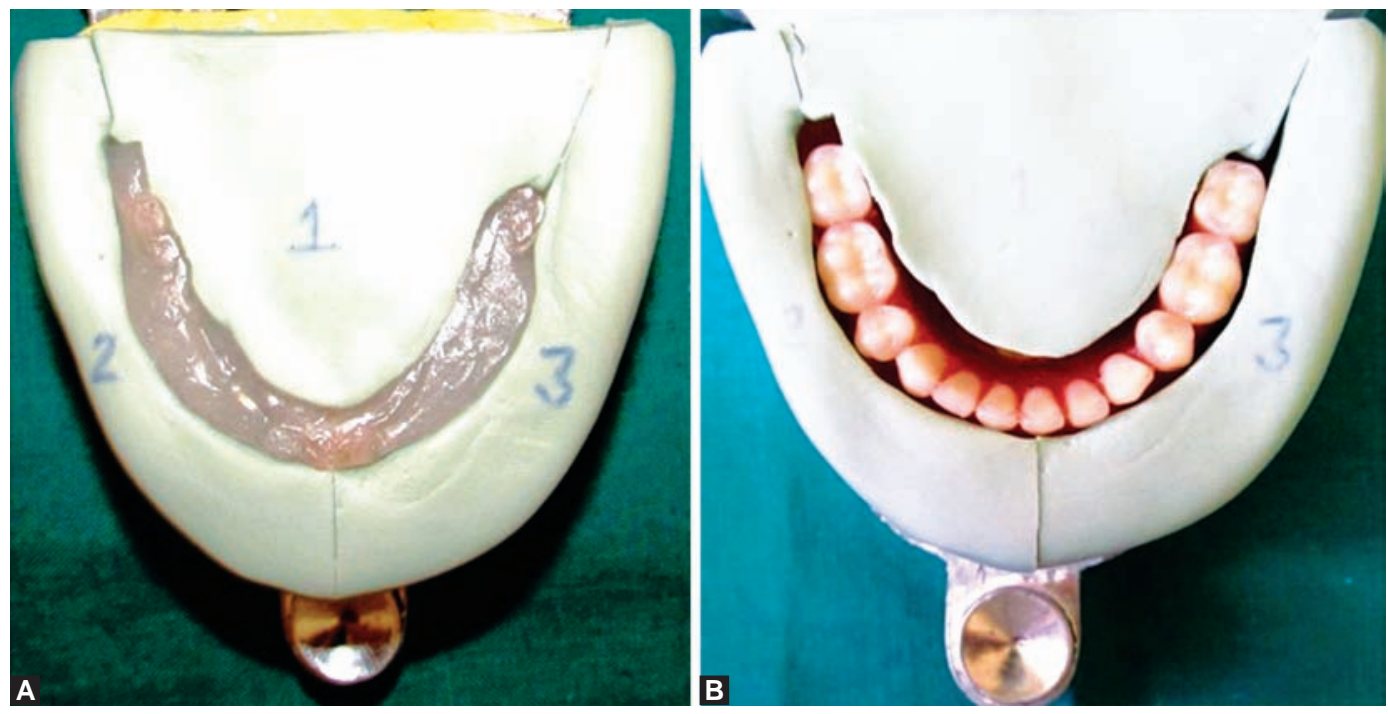

Figs 2A and B: (A) Silicone matrices made around neutral zone and (B) teeth arrangement done according to silicone matrices

conventional manner. After deflasking, cold mold seal (DPI, India) was applied on all surfaces of the investment of lower denture (Fig. 3A). To provide space for resilient liner (Molloplast ${ }^{\circledR}$ B-DETAX dental, Germany), 12 lead foil spacer sheets (Kodak periapical film) of $2 \mathrm{~mm}$ thickness were adapted over the ridge on the resin denture base (Fig. 3B). Heat cure acrylic resin (DPI, India) powder and liquid was mixed with a ratio of ( $3: 2$ by volume) and placed against the teeth in dough stage and a split packing technique was followed using a cellophane separator. The flasks were closed and kept for 20 minutes for bench press. The flasks were opened and cellophane sheet and lead foil spacer were discarded. Excess resin flash was removed. Primo adhesive liquid provided with the soft resilient liner Molloplast-B
(DETAX dental, Germany) was applied on the acrylic resin surface and allowed to dry for 20 minutes. The resilient material (Molloplast-B) was placed on the resin denture base in $2 \mathrm{~mm}$ space provided by the tin foil spacer. A trial packing was done and excess material was removed (Fig. 3C).

The flasks were closed and cured at $74^{\circ} \mathrm{C}$ for 2 hours with 1 hour terminal boiling. Deflasking was done and finishing and polishing procedures were completed (Figs 4 and 5). The dentures were delivered to the patient after occlusal adjustments.

\section{DISCUSSION}

Effect of traumatic impact over the edentulous ridge can be reduced by sandwiching a resilient resin layer within the 

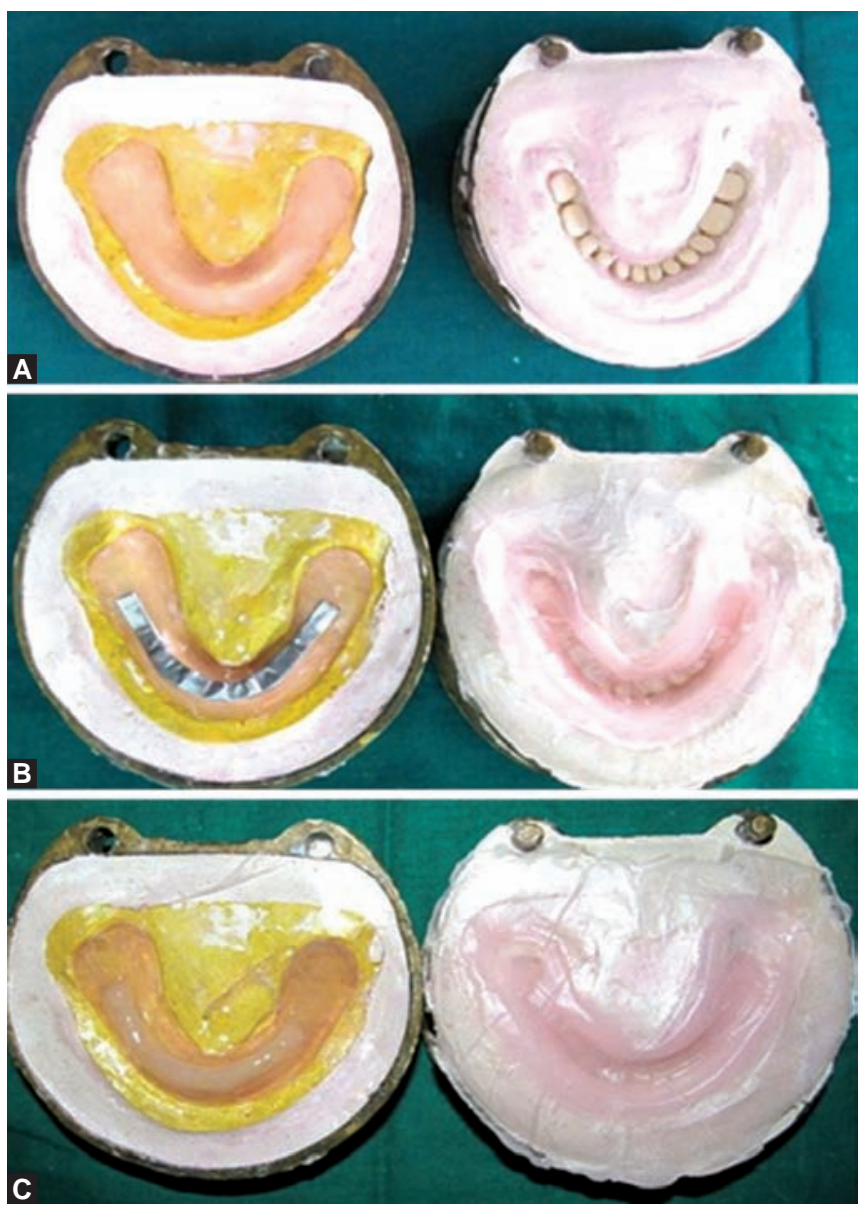

Figs 3A to C: (A) After Deflasking lead foil placed over record base, (B) and heat cure acrylic resin packed against the denture teeth, (C) Molloplast-B resilient material placed in a space created by lead foil

denture base. The resilient layer denture acts as a 'shock absorber' or 'stress distributor'. By bonding the resilient material to the resin base of the denture, the advantages of impact reduction are combined with the advantages of a hard denture base. The resilient material is compressed in function, but its area of contact with the hard parts of the denture base remains unchanged. The soft filler absorbs some of the kinetic energy applied to the teeth so that the hard basal seat of the denture receives less impact force. Part of the kinetic energy is dissipated in the deformation of the resilient layer. ${ }^{4}$

Resilient layer in the denture helps in the preservation of ridges and is more comfortable to wear due to less stress transmission to underlying tissues. ${ }^{5}$ Resilient layer denture is a viable alternative to conventional rigid denture for its effects on the residual ridge resorption.

According to Kawano et al, Molloplast-B demonstrated excellent shock absorption and found shock absorbability to be a function of the thickness of the resilient layer. ${ }^{6}$ The thickness of resilient layer was kept at $2 \mathrm{~mm}$ which was equivalent to the thickness of 12 sheets of lead foil (Kodak

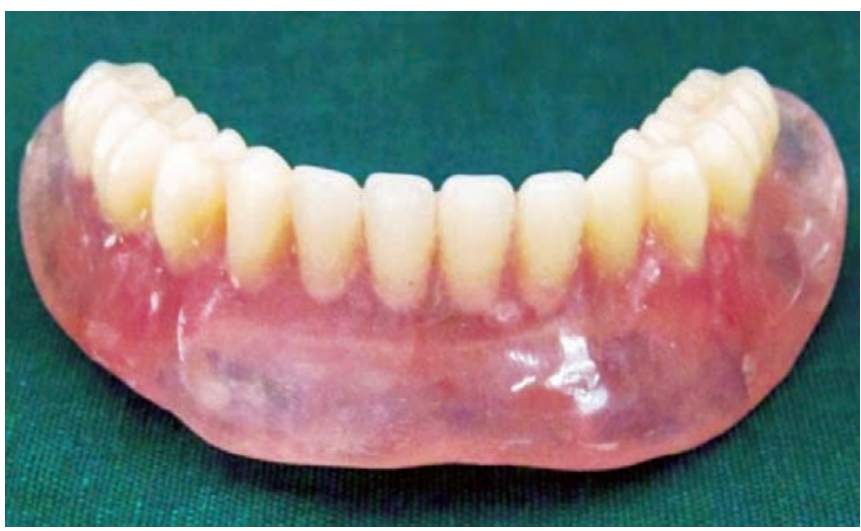

Fig. 4: Processed mandibular sandwich denture

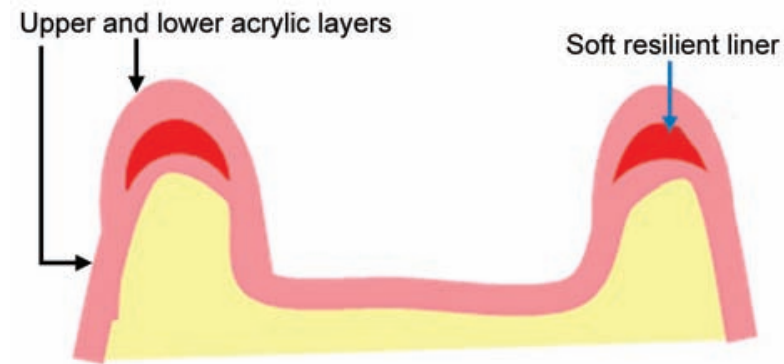

Fig. 5: Cross-section of a denture showing resilient liner between two acrylic layers

periapical film) used as a standard spacer. According to Plotnick, ${ }^{7}$ transmitted forces were reduced from 20 to $60 \%$ by using the resilient layer. To be effective, a resilient denture liner should be about 2 to $3 \mathrm{~mm}$ thick (Wright, 1976; Kazanji \& Watkinson, 1988). ${ }^{8,9}$

Numerous resilient materials have been evaluated for their physical properties, for long-term use in the oral cavity. Permanent resilient silicone rubber like Molloplast-B retains the viscoelasticity and softness for longer periods and does not harden due to lack of plasticizers. ${ }^{10}$

\section{CONCLUSION}

This article describes the step-by-step fabrication of sandwich dentures with slight modification of laboratory procedures used for conventional prosthesis.

\section{REFERENCES}

1. Kelsey CC. Alveolar bone resorption under complete dentures. J Prosthet Dent 1971;25:152-161.

2. Atwood DA. Reduction of residual ridges: a major oral disease entity. J Prosthet Dent 1971;26:266-279.

3. Parker HM. Impact reduction in complete and partial dentures. A pilot study. J Prosthet Dent 1966;16:227-245.

4. Bernhausen ER. Resilient material used between the teeth and the denture base: a preliminary report. J Prosthet Dent 1971;25: 258-264. 
5. Taguchi N, Murata H, Hamada T, Hong G. Effect of viscoelastic properties of resilient denture liners on pressures under dentures. J Oral Rehabil 2001;28:1003-1008.

6. Kawano F, Kar M, Koran A, Matsumota N. Shock absorbing behavior of four processed soft denture liners. J Prosthet Dent 1994;72:599-605.

7. Plotnick IJ. Stress regulators for complete and partial denture. J Prosthet Dent 1967;17:166-171.

8. Wright PS. Soft lining materials: their status and prospects. J Dent 1976;4:247-256.

9. Kazanji MN, Watkinson AC. Influence of thickness, boxing and storage on the softness of resilient denture lining materials. J Prosthet Dent 1988;59(6):677-680.

10. Hong G, Murata H, Hamada T. Relationship between plasticizer content and tensile bond strength of soft denture liners to a denture base resin. Dent Mater J 2004;23(2):94-99.

\section{ABOUT THE AUTHORS}

\section{Siddharth Bansal (Corresponding Author)}

Postgraduate Student, Department of Prosthodontics, Goa Dental College and Hospital, Goa, India, Phone: 7620079671 e-mail: siddharthbansal42@gmail.com

\section{Meena Aras}

Head, Department of Prosthodontics, Goa Dental College and Hospital Goa, India

\section{Vidya Chitre}

Associate Professor, Department of Prosthodontics, Goa Dental College and Hospital, Goa, India 